\title{
Vomiting after a pediatric adenotonsillectomy: comparison between propofol induced sevoflurane-nitrous oxide maintained anesthesia and TIVA with propofol-remifentanil
}

\author{
Ji-Hyun Chung ${ }^{2}$, Yoon-Hee Kim ${ }^{1}$, Young-Kwon $\mathrm{Ko}^{1}$, Sun-Yeul Lee ${ }^{1}$, Yoon-Tae Nam ${ }^{1}$, and Seok-Hwa Yoon ${ }^{1}$ \\ Department of Anesthesiology and Pain Medicine, ${ }^{1}$ Chungnam National University School of Medicine, ${ }^{2}$ Eulji University School of \\ Medicine, Daejeon, Korea
}

Background: Anesthesia methods and drugs affect postoperative nausea and vomiting. Propofol is known to have antiemetic effects. We compared the incidence of postoperative vomiting (POV) in children undergoing an adenotonsillectomy; anesthesia in one group was induced with propofol and maintained with sevoflurane and nitrous oxide, and the other group received total intravenous anesthesia (TIVA) with propofol-remifentanil.

Methods: Ninety children, ASA physical status I, were assigned randomly to one of two groups. In the PSN group, anesthesia was maintained with $2-3$ vol\% sevoflurane and $50 \%$ nitrous oxide. In the PR group, anesthesia was maintained with $10 \mathrm{mg} / \mathrm{kg} / \mathrm{h}$ propofol and $0.25 \mu \mathrm{g} / \mathrm{kg} / \mathrm{min}$ remifentanil. In both groups, anesthesia was induced with $0.5 \mu \mathrm{g} / \mathrm{kg}$ remifentanil and $2 \mathrm{mg} / \mathrm{kg}$ propofol. The incidence of POV and the need for rescue antiemetics were assessed in the postanesthesia care unit at 6, 12, and 24 hours postoperatively.

Results: The total incidence of POV was not significantly different between the groups; POV occurred in eight (17.7\%) and three (6.7\%) children in the PSN and PR groups, respectively. Postoperative frequency of retching in the recovery room was significantly higher in the PSN group, with four children (8.9\%) in the PSN group compared to none (0\%) in the PR group ( $\mathrm{P}=0.041)$. The frequency of POV $24 \mathrm{hrs}$ after exiting the recovery room tended to be higher in the PSN group than the PR group, but no statistically significant difference was observed.

Conclusions: If the development of POV in the early anesthetic recovery phase of children undergoing adenotonsillectomy is adequately prevented, propofol-induced anesthesia maintained with sevoflurane-nitrous oxide is as safe as TIVA with propofol-remifentanil. (Korean J Anesthesiol 2010; 59: 185-189)

Key Words: Adenotonsillectomy, Pediatric, PONV, Sevoflurane, TIVA.

\footnotetext{
Received: May 12, 2010. Revised: May 17, 2010. Accepted: May 31, 2010.

Corresponding author: Yoon-Hee Kim, M.D., Ph.D., Department of Anesthesiology and Pain Medicine, Chungnam National University School of Medicine, Daesa-dong, Jung-gu, Daejeon 301-721, Korea. Tel: 82-42-280-7840, Fax: 82-42-280-7968, E-mail: yhkim0404@cnu.ac.kr (c) This is an open-access article distributed under the terms of the Creative Commons Attribution Non-Commercial License (http:// creativecommons.org/licenses/by-nc/3.0/), which permits unrestricted non-commercial use, distribution, and reproduction in any medium, provided the original work is properly cited.
} 


\section{Introduction}

The incidence of postoperative vomiting (POV) following a pediatric adenotonsillectomy is $40-80 \%$, which is higher than strabismus surgery [1].

Postoperative nausea and vomiting (PONV) is called "the big little problem" [2], but severe vomiting is also a major cause of pediatric death because it can cause bleeding, dehydration, wound dehiscence, and aspiration pneumonia [3]. Even mild PONV may result in a delayed hospital discharge with increased costs, as well as decreased parental satisfaction and an unpleasant experience for the patient [4].

Anesthetic-related factors that affect the incidence of PONV include premedication, intraoperative anesthetic methods and drugs, and postoperative factors such as pain management and timing of oral food intake [3].

Apfel et al. [5] reported that volatile anesthetics were the leading cause of early POV. Compared with isoflurane, total intravenous anesthesia (TIVA) with propofol and remifentanil resulted in a significantly lower incidence of PONV [6]. However, TIVA has some limitations compared with inhalation anesthesia in children. Although the same dose of propofol is administered to children, a great discrepancy exists in its plasma level among individual children [7], and it is also difficult to predict the plasma concentration of anesthetic agents in a noninvasive manner [8]. There is no optimal dose of TIVA agents based on age [8], and the reliability of a BIS monitor, which is used to monitor the depth of anesthesia, cannot be trusted in children aged 5 years or younger [9]. Therefore, it can be inferred that TIVA has a lower degree of usefulness than inhalation anesthesia in children undergoing surgery in which the incidence of PONV is relatively higher. According to Simurina et al. [10] no significant difference was observed in the incidence of POV between a group of children who underwent an adenotonsillectomy, in which anesthesia was induced with propofol-fentanyl and then maintained, and that done using sevoflurane. As described here, controversial opinions still exist regarding the effects of TIVA for preventing PONV in children.

Although controversial, some studies have reported that the incidence of PONV is significantly lower in patients who were induced by propofol and then maintained with inhalation agents as compared with those who were induced by thiopental $[11,12]$. However, most of these studies were conducted in adults.

Given the above background, we compared the incidence of POV in children undergoing an adenotonsillectomy; anesthesia in one group was induced with propofol and maintained with sevoflurane and nitrous oxide, while the other group was induced with propofol-remifentanil and maintained with TIVA.

\section{Materials and Methods}

We studied 90 ASA I or II children aged 3-16 years who were scheduled for a tonsillectomy with or without an adenoidectomy under general anesthesia. The study was approved by the local institutional ethics committee, and written informed parental consent was obtained. The following cases were excluded from the study; patients with central nervous system disorders, those with recent or chronic administration of sedative drugs, those who had experienced POV, those who had taken an antiemetic medication within 24 hours before surgery, and those who had a history of motion sickness.

Patients were fasted after the midnight before surgery. Clear liquids were permitted up to 3 hours before surgery. Thirty minutes prior to anesthesia induction, all patients were premedicated with midazolam $(0.04 \mathrm{mg} / \mathrm{kg})$ and glycopyrrolate (0.004 mg/kg) intravenously (IV).

Upon arrival in the operating room, electrocardiogram, heart rate, and oxygen saturation were monitored continuously, and non-invasive arterial blood pressure was recorded at 5-minute intervals throughout the procedure. Patients were randomly selected and then classified into two groups: the PSN group in which anesthesia was induced with propofol and then maintained with sevoflurane and nitrous oxide $(n=45)$ and the PR group in which TIVA was performed with propofol and remifentanil $(\mathrm{n}=45)$. All patients were induced with $2 \mathrm{mg} / \mathrm{kg}$ propofol IV, following a 20-second administration of $0.5 \mu \mathrm{g} / \mathrm{kg}$ remifentanil IV. After intubation, anesthesia was maintained with $2-3$ vol\% sevoflurane and $50 \%$ nitrous oxide in oxygen in the PSN group, and in the PR group anesthesia was maintained with a continuous infusion of $10 \mathrm{mg} / \mathrm{kg} / \mathrm{h}$ propofol IV, $0.25 \mu \mathrm{g} /$ $\mathrm{kg} / \mathrm{min}$ remifentanil IV, and $50 \%$ nitrous oxide in oxygen. During surgery, maintenance doses of anesthetics were adjusted to maintain blood pressure within $\pm 20 \%$ of baseline in each group. In both groups, $0.6 \mathrm{mg} / \mathrm{kg}$ rocuronium IV was administered to all patients to facilitate endotracheal intubation, and no further doses were administered. Controlled ventilation was conducted to sustain the end-tidal carbon dioxide between 35 and $40 \mathrm{mmHg}$. A tonsillectomy was performed using an electrodissection technique, and the adenoidectomy was performed using palliative curettage. All patients received 1 $\mathrm{mg} / \mathrm{kg}$ ketorolac IV 20 minutes prior to the end of surgery for pain control and $10 \mathrm{ml} / \mathrm{kg}$ lactated Ringer's solution during the operation. At the end of surgery, the neuromuscular blockade was reversed by a combination of $0.2 \mathrm{mg} / \mathrm{kg}$ pyridostigmine IV and $0.008 \mathrm{mg} / \mathrm{kg}$ glycopyrrolate IV, and gastric contents were suctioned via an orogastric tube before extubation. Patients were extubated once end-tidal sevoflurane concentrations were less than $0.2 \%$ and extubation criteria were met, which was defined as a positive head lift, hand grip, and eye-opening 
following on command. All children were transferred to the postanesthesia care unit (PACU). The criteria for discharge from the PACU to the ward included stable vital signs, adequate pain control, and absence of vomiting for 1 hour.

In the PACU, and during the first 24 hours after discharge from the PACU on the ward, all episodes of emetic symptoms (retching, vomiting) were recorded at regular intervals. Vomiting was defined as the forceful expulsion of gastric contents from the mouth; retching was defined as the labored, spasmodic, rhythmic contraction of the respiratory tract muscles, including the diaphragm, chest wall, and abdominal wall muscles without expulsion of gastric contents. Nausea was not assessed as a separate entity in this study considering that the patients were young. Retching and vomiting were inclusively defined as POV. Data were collected at the PACU and thereafter in the ward at 4,12 , and 24 hours. Vomiting that occurred more than twice was treated with $0.06 \mathrm{mg} / \mathrm{kg}$ ondansetron IV. In children who complained of severe postoperative pain, $1 \mathrm{mg} / \mathrm{kg}$ ketorolac sodium was additionally injected IV. The volume of fluid therapy was adjusted postoperatively, depending on blood loss, POV, and oral intake.

The statistical analysis was performed using SPSS 11.5. Measurements were expressed as mean \pm standard deviation or percentile values (\%). Differences between the groups were tested using unpaired Student's t-tests. PONV incidence was compared using the chi-square test. $\mathrm{P}<0.05$ was considered statistically significant.

\section{Results}

No statistically significant differences were observed between the two groups with respect to age, body weight, body height, gender ratio, fluid volume during anesthesia, surgery duration, anesthesia, or the number of children who were additionally

Table 1. Patient Data

\begin{tabular}{lcc}
\hline & $\begin{array}{c}\text { PSN group } \\
(\mathrm{n}=45)\end{array}$ & $\begin{array}{c}\text { PR group } \\
(\mathrm{n}=45)\end{array}$ \\
\hline Gender (M/F) & $26 / 19$ & $27 / 18$ \\
Age (years) & $7.9 \pm 3.2$ & $8.0 \pm 3.7$ \\
Weight (kg) & $29.3 \pm 12.6$ & $33.5 \pm 15.9$ \\
Height (cm) & $126.8 \pm 18.8$ & $129.7 \pm 21.5$ \\
Volume of fluids during anesthesia (ml/kg) & $10.4 \pm 0.8$ & $10.6 \pm 1.8$ \\
Duration of surgery (min) & $40.8 \pm 13.7$ & $39.1 \pm 11.5$ \\
Duration of anesthesia (min) & $64.9 \pm 15.2$ & $62.1 \pm 12.0$ \\
Number of patient requiring analgesics & 1 & 0 \\
Surgical procedure & & 5 \\
$\quad$ Tonsillectomy (n) & 9 & 40 \\
$\quad$ Adenotonsillectomy (n) & 36 & 5 \\
\hline
\end{tabular}

Values are mean \pm SD or number. PSN group: anesthesia induction with propofoland maintained with sevoflurane/nitrous oxide, PR group: total intravenous anesthesia with propofol and remifentanil. given ketorolac following the surgery. The surgical procedures were similar in the two groups (Table 1).

The overall incidence of POV was three children (6.7\%) in the PR group and eight children (17.7\%) in the PSN group $(\mathrm{P}>0.05)$. More patients in the PSN group (4 children, 8.9\%) experienced retching than in the PR group ( 0 children, $0 \%)$ in the PACU ( $\mathrm{P}=$ 0.041). POV occurred most frequently in the first 6 hours after discharge from the PACU (2 cases [4.4\%] in the PR group and 7 cases [15.5\%] in the PSN group; Table 2).

All children were well oxygenated throughout the study period, and no airway complications were noted. No patient received ondansetron in the PACU or the ward.

\section{Discussion}

The incidence of POV in the PACU was significantly lower in the group that received TIVA with propofol and remifentanil compared with those who received sevoflurane and nitrous oxide. However, no differences in the incidences of POV were found after discharge from the PACU.

Sevoflurane is a well-tolerated inhalation induction agent in all age groups, because it is pleasant smelling and relatively non-irritating to the airways [13]. Due to the low blood and tissue solubilities and cardiopulmonary stability, it is a suitable anesthetic for ambulatory surgery in infants and children [14]. The use of sevoflurane for ENT surgery in children has been compared with halothane, but PONV is more frequent after

Table 2. Number (\%) of Patients Experiencing No Emesis, Retching, or Vomiting

\begin{tabular}{lcc}
\hline & $\begin{array}{c}\text { PSN group } \\
(\mathrm{n}=45)\end{array}$ & $\begin{array}{c}\text { PR group } \\
(\mathrm{n}=45)\end{array}$ \\
\hline PACU & $41(91)$ & $45(100)$ \\
Emesis-free & $4(8.9)$ & $0 *$ \\
Retching & $2(4.4)$ & 0 \\
Vomiting & & \\
0-6 hours after discharge from PACU & 38 & 43 \\
Emesis-free & $6(13.3)$ & $2(4.4)$ \\
Retching & $1(2.2)$ & 0 \\
Vomiting & & $45(100)$ \\
6-12 hours after discharge from PACU & 0 & 0 \\
Emesis-free & 0 & $1(2.2)$ \\
Retching & & \\
Vomiting & $45(100)$ & $45(100)$ \\
12-24 hours after discharge from PACU & 0 & 0 \\
Emesis-free & 0 & 0 \\
Retching & & $3(6.7)$ \\
Vomiting & $8(17.7)$ & $37.8)$ \\
Total & & \\
Overall POV & & \\
\hline
\end{tabular}

PSN group: anesthesia induction with propofol, maintained with sevoflurane/nitrous oxide, PR group: total intravenous anesthesia with propofol and remifentanil, PACU: postanesthesia care unit. *P $<0.05(\mathrm{P}=0.041)$ versus group PSN. 
halothane anesthesia [15].

Compared with propofol, sevoflurane shows a similar pattern in the maintenance or recovery from anesthesia, or, conversely, it may result in a more prompt recovery from anesthesia than propofol. However, the incidence of PONV after sevoflurane anesthesia is higher than that with propofol $[16,17]$. According to Ved et al. [18] the incidence of POV was relatively lower in the first six hours in patients for whom anesthesia was induced with propofol compared to halothane, but thereafter no significant difference was observed. Also Tramer et al. [19] following a meta-analysis of the literature, found that TIVA with propofol, rather than inhalation anesthesia, may have a clinically relevant effect on PONV but only in the short term. Similarly, according to Fredmann et al. [16] the incidence of PONV was lower during the first two hours of the early postoperative stage in outpatients under general anesthesia with propofol than those for whom anesthesia was induced with sevoflurane, and no significant difference was observed thereafter. In this study, the incidence of PONV was significantly lower only at the PACU in the TIVA group, and this agreed with previous reports that TIVA methods with propofol reduced the occurrence of nausea and vomiting during the early postoperative stage.

Propofol prevents PONV by playing a role blocking 5-hydroytryptamine-3 receptors [20] or by directly inhibiting not only the chemoreceptor trigger zone in the CNS but also the vagus nerve, which is associated with nausea and vomiting [21]. But, controversial opinions exist regarding the effects on PONV in cases in which propofol was administered to induce anesthesia. Chanvej et al. [11] reported that the incidence of PONV decreased by $28 \%$ in a group in which anesthesia was induced with propofol as than when it was induced with thiopental sodium in outpatients who underwent laparoscopic surgery. Furthermore, Chia et al. [12] reported that propofol was effective for preventing PONV when it was used as an induction anesthesia agent. According to Grundmann et al. [22] no significant difference in the occurrence of PONV was observed at a recovery room between a group in which TIVA was performed using propofol-remifentanil and that in which anesthesia was induced using propofol and then maintained using desflurane-nitrous oxide. However, in this study, the incidence of retching was significantly higher at the PACU in the group that received propofol than in a group in which TIVA was performed. These results were in agreement with those of Park et al. [23] in patients who underwent laparoscopic cholecystectomy, and those of Gan et al. [24].

In the current study, POV developed intensively during the first 6 hours following discharge from the PACU in the group that was induced with propofol and maintained using sevofluranenitrous oxide. According to Ariffin et al. [25] following anesthesia with sevoflurane or halothane in outpatients, the incidence of PONV prior to the discharge was relatively higher in the sevoflurane group, but it was significantly higher following discharge in the halothane group. These authors explained that sevoflurane has a faster clearance rate than halothane in an in vivo setting. Sevoflurane has a half-life that is five times shorter than that of halothane [26]. Accordingly, the incidence of vomiting was relatively higher in the PACU, then within 2 hours postoperatively, and in most cases, vomiting symptoms disappeared within 24 hours [27]. The pattern of PONV in the sevoflurane group shown in this study was similar to the pharmacokinetic profile of sevoflurane.

Remifentanil has a context-sensitive half-life of approximately 3-6 minutes, but it is not subject to the injection time, and once injection is stopped, its action promptly disappears. Thus, recovery from anesthesia can be predicted [28]. However, the incidence of nausea and vomiting appears similar to other opioids. In children who underwent a tonsillectomy under general anesthesia using sevoflurane or halothane, POV occurred at incidences of $10 \%$ and $12 \%$ in a remifentanil group and $10 \%$ and $13 \%$ in a fentanyl group [29].

There is also controversy as to the effects of nitrous oxide on PONV. According to Splinter and Komocar [30] the incidence of POV was relatively higher in children who received dental treatments with nitrous oxide than other agents. However, these authors noted that there was no effect on the overall incidence of POV.

In the current study, the overall incidence of POV was $17.7 \%$ in the group in which anesthesia was induced with propofol and then maintained with $6.7 \%$ sevoflurane-nitrous oxide. This might be due not only to propofol/TIVA but also surgical time was relatively shorter and other factors such as the effects of midazolam, which was administered prior to anesthesia, and the exclusion of children with a past history of motion sickness or PONV.

In conclusion, the overall incidence of POV was relatively lower in a group in which TIVA was maintained using propofolremifentanil rather than a group in which anesthesia was induced using propofol and then maintained using sevofluranenitrous oxide. Following a comparison of the time-dependent incidence of POV between the two groups, the incidence of POV at the PACU was relatively lower in the TIVA group. However, during the 24-hr period thereafter, no significant difference was observed between the two anesthetic methods. Based on these results, it can be inferred that the methods in which anesthesia is induced with propofol and maintained with sevofluranenitrous oxide would have a similar profile of safety to those in which TIVA is performed using propofol- remifentanil.

\section{References}

1. Lerman J. Surgical and patient factors involved in postoperative 
nausea and vomiting. Br J Anaesth 1992; 69: 24S-32S.

2. Kapur PA. The big "little problem". Anesth Analg 1991; 73: 243-5.

3. Rose JB, Watcha MF. Postoperative nausea and vomiting in paediatric patients. Br J Anaesth 1999; 83: 104-17.

4. Watcha MF, Smith I. Cost-effectiveness analysis of antiemetic therapy for ambulatory surgery. J Clin Anesth 1994; 6: 370-7.

5. Apfel CC, Kranke P, Katz MH, Goepfert C, Papenfuss T, Rauch S, et al. Volatile anaesthetics may be the main cause of early but not delayed postoperative vomiting: a randomized controlled trial of factorial design. Br J Anaesth 2002; 88: 659-68.

6. Ionescu D, Margarit S, Vlad L, Iancu C, Alexe A, Deac D, et al. TIVATCI (Total IntraVenous Anesthesia-Target Controlled Infusion) versus isoflurane anesthesia for laparoscopic cholecystectomy. Postoperative nausea and vomiting, and patient satisfaction. Chirurgia (Bucur) 2009; 104: 167-72.

7. Hannallah RS, Baker SB, Casey W, McGill WA, Broadman LM, Norden JM. Propofol: effective dose and induction characteristics in unpremedicated children. Anesthesiology 1991; 74: 217-9.

8. Lerman J, Johr M. Inhalational anesthesia vs total intravenous anesthesia (TIVA) for pediatric anesthesia. Paediatr Anaesth 2009; 19: 521-34.

9. Wallenborn J, Kluba K, Olthoff D. Comparative evaluation of Bispectral Index and Narcotrend Index in children below 5 years of age. Paediatr Anaesth 2007; 17: 140-7.

10. Simurina T, Mikulandra S, Mraovic B, Sonicki Z, Kovacic M, Dzelalija B, et al. The effect of propofol and fentanyl as compared with sevoflurane on postoperative vomiting in children after adenotonsillectomy. Coll Antropol 2006; 30: 343-7.

11. Chanvej L, Kijsirikul S, Thongsuksai P, Naheem L. Post-operative nausea and vomiting in out-patient gynecologic laparoscopy: a comparison of thiopental-nitrous oxide, propofol-nitrous oxide and total intravenous anesthesia using propofol. J Med Assoc Thai 2001; 84: 697-704.

12. Chia YY, Lee SW, Liu K. Propofol causes less postoperative pharyngeal morbidity than thiopental after the use of a laryngeal mask airway. Anesth Analg 2008; 106: 123-6.

13. Smith I, Nathanson M, White PF. Sevoflurane--a long-awaited volatile anaesthetic. Br J Anaesth 1996; 76: 435-45.

14. Holzman RS, van der Velde ME, Kaus SJ, Body SC, Colan SD, Sullivan LJ, et al. Sevoflurane depresses myocardial contractility less than halothane during induction of anesthesia in children. Anesthesiology 1996; 85: 1260-7.

15. Johannesson GP, Floren M, Lindahl SG. Sevoflurane for ENTsurgery in children. A comparison with halothane. Acta Anaesthesiol Scand 1995; 39: 546-50.

16. Fredman B, Nathanson MH, Smith I, Wang J, Klein K, White PF. Sevoflurane for outpatient anesthesia: a comparison with propofol. Anesth Analg 1995; 81: 823-8.

17. Raeder J, Gupta A, Pedersen FM. Recovery characteristics of sevoflurane- or propofol-based anaesthesia for day-care surgery. Acta Anaesthesiol Scand 1997; 41: 988-94.

18. Ved SA, Walden TL, Montana J, Lea DE, Tefft MC, Kataria BK, et al. Vomiting and recovery after outpatient tonsillectomy and adenoidectomy in children. Comparison of four anesthetic techniques using nitrous oxide with halothane or propofol. Anesthesiology 1996; 85: 4-10.

19. Tramer M, Moore A, McQuay H. Propofol anaesthesia and postoperative nausea and vomiting: quantitative systematic review of randomized controlled studies. Br J Anaesth 1997; 78: 247-55.

20. Barann M, Gothert M, Fink K, Bonisch H. Inhibition by anaesthetics of 14C-guanidinium flux through the voltage-gated sodium channel and the cation channel of the 5-HT3 receptor of N1E-115 neuroblastoma cells. Naunyn Schmiedebergs Arch Pharmacol 1993; 347: 125-32.

21. Appadu BL, Strange PG, Lambert DG. Does propofol interact with D2 dopamine receptors? Anesth Analg 1994; 79: 1191-2.

22. Grundmann U, Uth M, Eichner A, Wilhelm W, Larsen R. Total intravenous anaesthesia with propofol and remifentanil in paediatric patients: a comparison with a desflurane-nitrous oxide inhalation anaesthesia. Acta Anaesthesiol Scand 1998; 42: 845-50.

23. Park HH, Park KS, Lee SY, Cho OG, Kim JH, Kim JS, et al. The Effects of Prophylactic Metoclopramide and Induction with Propofol on Postoperative Nausea and Vomiting. Korean J Anesthesiol 2006; 50: 179-83.

24. Gan TJ, Ginsberg B, Grant AP, Glass PS. Double-blind, randomized comparison of ondansetron and intraoperative propofol to prevent postoperative nausea and vomiting. Anesthesiology 1996; 85: 103642.

25. Ariffin SA, Whyte JA, Malins AF, Cooper GM. Comparison of induction and recovery between sevoflurane and halothane supplementation of anaesthesia in children undergoing outpatient dental extractions. Br J Anaesth 1997; 78: 157-9.

26. Epstein RH, Mendel HG, Guarnieri KM, Staudt SR, Lessin JB, Marr AT. Sevoflurane versus halothane for general anesthesia in pediatric patients: a comparative study of vital signs, induction, and emergence. J Clin Anesth 1995; 7: 237-44.

27. Andrews PL. Physiology of nausea and vomiting. Br J Anaesth 1992; 69: 2S-19S.

28. Egan TD, Minto CF, Hermann DJ, Barr J, Muir KT, Shafer SL. Remifentanil versus alfentanil: comparative pharmacokinetics and pharmacodynamics in healthy adult male volunteers. Anesthesiology 1996; 84: 821-33.

29. Davis PJ, Finkel JC, Orr RJ, Fazi L, Mulroy JJ, Woelfel SK, et al. A randomized, double-blinded study of remifentanil versus fentanyl for tonsillectomy and adenoidectomy surgery in pediatric ambulatory surgical patients. Anesth Analg 2000; 90: 863-71.

30. Splinter WM, Komocar L. Nitrous oxide does not increase vomiting after dental restorations in children. Anesth Analg 1997; 84: 506-8. 